\title{
Continuum, continuity, continuum actions: reflection on the meaning of a continuum perspective and on its compatibility with a life cycle framework
}

\author{
Viviane Frings-Hessami ${ }^{1}[$
}

Accepted: 26 September 2021 / Published online: 5 October 2021

(c) The Author(s), under exclusive licence to Springer Nature B.V. 2021

\begin{abstract}
Archival concepts are grounded in cultural traditions and often difficult to translate because equivalent terms do not exist. This may lead to misunderstandings which may impact on intercultural understanding and international collaboration. This article looks at how the Records Continuum Model, which was developed in Australia in the 1990s in response to the perceived deficiencies of the life cycle model to deal with digital records, is understood by francophone archivists and records managers. Misunderstandings can be attributed to problems of translation and transposition of Records Continuum ideas in other archival contexts, as well as to the specific terminology, which in itself is confusing because the terms used-in particular records, recordkeeping and continuum-have meanings that differ from their meanings in everyday language or in other cultural contexts. Through interviews with francophone archivists in Switzerland, the author explored their understanding of the model and the measures they were trying to put in place to encourage the creation of records and their preservation for as long as they would be needed by various stakeholders. The author shows that although the interviewees were all working within a life cycle framework, some of them were taking small "continuum actions" that can have a significant impact on the creation, management and preservation of records and on their ability to meet the needs of various stakeholders.
\end{abstract}

Keywords Records Continuum Model $\cdot$ Records Continuum perspective $\cdot$ Life cycle model · Translation of archival terminology $\cdot$ Intercultural understanding · Francophone archivists

Viviane Frings-Hessami

Viviane.Hessami@monash.edu

1 Faculty of Information Technology, Monash University, Dandenong Road, Caufield East, VIC 3145, Australia 


\section{Introduction}

Archival concepts are grounded in cultural traditions and can be difficult to translate in other languages because equivalent terms may not exist or because apparently similar terms actually refer to different concepts (Ketelaar 1997). Translation problems may lead to misunderstandings which may impact on intercultural understanding and international collaboration. One example of an archival model that is often misunderstood is the Records Continuum Model developed in Australia in the 1990s. This model, which was devised to address the issues brought about by digital records, may prove useful for archivists in other countries and cultures who are battling with similar problems and finding life cycle models hard to implement for digital records. This article looks at how the model has been understood by francophone archivists and discusses how a Records Continuum perspective can be used to help meet the needs of various records stakeholders even when working in a life cycle framework.

In an article in French published in Archivaria in 2014, Yvon Lemay and Anne Klein argued that the Records Continuum Model ends with the transfer of records to archival institutions and suggested adding a fifth dimension to the Records Continuum Model to accommodate the exploitation of archives (Lemay and Klein 2014). These comments reflect a linear reading of the Records Continuum. The model developed by Frank Upward was not intended to be read in a linear way. It was designed as a multidimensional and recursive model in opposition to the linearity of the life cycle model whose stages follow one another in a predetermined way. From a Records Continuum perspective, there is not an end stage, records are always becoming (McKemmish 1994, p. 200), always susceptible to be used in a different way by a different actor. After records are pluralised, they are susceptible to be reused, recreated, recaptured, reorganised and repluralised. Every reuse of a record brings it back to the first dimension, that of action and creation.

Misunderstandings of the model are common among francophone archivists and records managers (as well as among English speakers). They can be attributed to the theoretical complexity of some of the foundational Records Continuum writings, but also to the terminology used. The term records itself are confusing because it has different meanings in different English-speaking countries and because it does not have an exact translation in French. This is a well-known issue (Duchein 1985; Soum-Paris 2021; Ketelaar 1997, 2001; Gilliland 2017). However, there is a second terminological issue, which has not received attention in the archival literature, that of the meaning of "continuum" in Records Continuum. The term could appear to suggest, in accordance with the common use of the word, a linear continuity from documents to archives, whereas, in this particular case, it is used to indicate multidimensional recursive processes through time and space. "In Records Continuum theory, records exist in a spacetime continuum where they can be studied from different angles at the same time in the four dimensions of the Records Continuum Model"(Frings-Hessami and McKemmish 2021). This is to be "distinguished from a linear continuity between records 
and archives". In Records Continuum theory, records "do not reach an end product when they are pluralized" (Frings-Hessami and McKemmish 2021).

In this article, I report on a study that assessed whether francophone archivists in Switzerland understand the Records Continuum Model, and that investigated the measures they take to ensure that the records needed to meet societal expectations are created, managed and preserved so that they will be available when needed. The article starts with a brief explanation of the Records Continuum Model and of its key terminology and with a review of the rare mentions of the model in the archival literature in French. Then, the report of the findings of my interviews with Swiss archivists leads to a discussion of the essence of the Records Continuum and of the possibility of "continuum actions" that may help to incorporate the perspectives of various stakeholders into recordkeeping processes in a life cycle framework. The paper concludes with a reflection on the compatibility of a Records Continuum perspective with life cycle models.

\section{The Records Continuum Model}

The Records Continuum Model was developed at Monash University in Australia in the 1990s by Frank Upward and his colleagues as a tool to represent the contexts of records creation, management and use over time and space (Upward 1996, 1997). The model includes four dimensions: Create, Capture, Organise and Pluralise, which correspond to four types of processes that can be applied to records: the creation of documents, their capture in recordkeeping systems, their organisation into archives and their pluralisation to meet the needs of various stakeholders. These dimensions are simultaneous, enabling the representation of multiple perspectives of multiple actors over time and space (McKemmish et al. 2010). Recordkeeping (written in one word) encompasses the management of records and archives, as well as the setting up of recordkeeping systems before records are created, to meet the needs of a variety of stakeholders (McKemmish 2001). This is to be contrasted with life cycle models which are based on strict separations between current records and archives and between the roles of records managers and archivists (Williams 2006; Millar 2017).

Besides the term recordkeeping, other terms used in Records Continuum writings, including the words "records" and "continuum" and the labels on the Records Continuum Model, can be confusing for English speakers who use them in different ways, and even more so for people whose first language is not English. Many European archival traditions do not have a word equivalent to the English concept of "record". In France, archives are called archives from the time they are created. The 1979 Law on Archives (Art. 1) defined archives as: "all the documents, whatever their date, their form and their material support, created or received by a natural or legal person, and by all services or organisations in pursuance of their activities." There is no exact translation for the word "record" in French. The translation used in the first edition of ISO 15489, adopted in 2001, document d'archives, is one of the most commonly used. However, other translations are used as well. Documents and archives are commonly used. Documents à archiver (documents to be archived) 
and documents archivés (documents that have been archived) - depending on the context-are used in the European standard MoReq2, while the translation documents engageants, which highlight the evidential characteristics of records, is used in ISO 16175 (Chabin 2012). The translation document d'activité (activity document) adopted in the 2016 edition of ISO 15489, which is commonly used in Quebec, is unpopular and rarely used in France or in Switzerland. Archivists also make a distinction between archives courantes et intermediaires (current and semi-current records) which are used to support current business needs and archives définitives (permanent records) which are kept in archival repositories for their historical and cultural value. The different meanings of the word "archives" in French and in English and the absence of an exact translation for the word "record" can impact on French-speaking archivists' understanding of the Records Continuum. As I will show in this article, the specific meaning of the word "continuum" may also cause confusion and misunderstandings.

Records Continuum theory may appear complex. Some of Frank Upward's writings are very dense (Piggott 2012). However, the concepts that underpin the model can be explained in simple terms. The essence of the Records Continuum can be summarised in two points:

- Different processes can be applied to records at the same time to meet the needs of various stakeholders, and

- Recordkeeping processes are not aiming at producing an end product because records are always susceptible to be used in different ways by other stakeholders.

A Records Continuum perspective, therefore, consists of considering all the possible uses of the records and all the people who will need those records before they are created; and Records Continuum practice will aim at developing systems that will make it possible for all the stakeholders to access and use the records when they need them, and that will protect the rights of the people whose information is included in the records. These are what I use in this article as the key criteria to assess the thinking and practices of the Swiss archivists I interviewed from a Records Continuum perspective.

\section{The life cycle and the Records Continuum in the francophone literature}

The French theory of the "three ages of archives" ("les trois âges des archives") was first articulated by Yves Pérotin in 1961 in an article published in the journal Seine et Paris in which he proposed a method to manage archives based on three ages or stages: the stage of current archives when they are used regularly by their producers; an intermediary stage when the archives are used less frequently, but kept in a storeroom attached to the office that created them because they could still be useful; and a third stage when the archives are no longer useful to their producers and can be transferred to an archival repository if they have historical value (Pérotin 1961, p. 31; Pérotin 1966). French archival literature distinguishes between three categories 
of archives, which correspond to these three stages: archives courantes (current records), archives intermédiaires (semi-current records) and archives définitives (permanent records), and different procedures apply to each category (Direction des Archives de France 1993). This model is also widely used in the French-speaking parts of Switzerland and in Quebec (Rousseau and Couture 1994).

A review of the French archival literature reveals a paucity of articles on the Records Continuum Model. The article by Lemay and Klein (2014) mentioned previously is the only article on the Records Continuum Model published in French in Archivaria, and it neglects some key characteristics of the model. The authors acknowledge that the Records Continuum "aims to be non-linear", "favours a multidimensional view" that is open to various readings and interpretations, and "aims to fulfil various uses of records in domains such as education, research, professional practice, etc." (Lemay and Klein 2014, pp. 84-85, my translation). However, their argument that the Records Continuum ends with the fourth dimension and their suggestion of an additional fifth dimension to encompass the use (exploitation) of records after they are transferred to an archival repository to be kept permanently as historical archives (Lemay and Klein 2014, p. 100) amounts to a linear reading of the model. To align with Records Continuum thinking, a "use" dimension should encompass all the possible uses of records from their creation, not be restricted to the uses of permanent archives. I do not believe that such an additional dimension would be helpful because all the four dimensions are already ultimately concerned with the use of records: records are created, captured, organised and pluralised so that various stakeholders can use them to meet their needs in different ways.

In a paper presented at the 2014 ICA conference in Girona, Klein wrote that the Records Continuum is "linear" and "as its name indicates, continuous" (Klein 2014, p. 15, my translation). This reflects a misunderstanding of the meaning of continuum in Records Continuum thinking. In her 2019 book, Archive(s), memoire, art (Archive(s), memory, art), Klein further argued that "the records continuum model does not contradict in substance the approach of the three ages", but that "it gathers and highlights the diverse elements on which the stages of the life cycle are based" (Klein 2019, p. 108, my translation). These comments neglect the essential differences between the Records Continuum and life cycle models which reside in the rejection of linearity and the simultaneity of the dimensions encapsulated in Records Continuum theory.

No article has been published on the Records Continuum Model in La Gazette des archives, the journal of the Association of French Archivists, and only brief mentions (e.g. Rajotte 2010-11, pp. 83-85) can be found in Archives, the journal of the Quebec Association of Archivists. An article on records management in Geneva published in La Gazette des archives in 2005 mentioned the Records Continuum in its title, but it did not explain the model, and given the way the authors described collaboration between archivists and records managers in a life cycle framework, it would have been more appropriate to speak of continuity (continuité in French) or of a continuum (continuum in French) without associating the ideas with the Records Continuum. Sentences such as: "The continuum in the management of information and documents is thereby ensured throughout the life cycle" (Bagnoud et al. 2005 , p. 104) belong to a life cycle perspective rather than to a Records Continuum 
perspective. The meaning of "continuum" in that sense is one of continuity, not one of simultaneity of processes. What the authors call "a policy of Records Continuum" (Bagnoud et al. 2005, p. 104) could have been more appropriately described as a continuity throughout the life cycle of records.

The Records Continuum remains largely unknown in France and in Frenchspeaking Switzerland. This is attested by the fact that 2019 , around twenty-five years after its invention, a brief explanation of the model was published in the "News" section of the Association of French Archivists newsletter (Frings-Hessami 2019). Moreover, the model is often misunderstood and sometimes assimilated to a variant of a life cycle model (Kern et al. 2015). In a paper entitled "Cinquante nuances de cycle de vie" ("Fifty nuances of the life cycle") published in Les Cahiers du numérique in 2015, Gilliane Kern, Sandra Holgado and Michel Cottin presented the Records Continuum model as one "approach to the life cycle" (p. 60, my translation). The fact that the specific meaning given to the term "continuum" in Records Continuum theory differs significantly from the common usage of the terms "continuum" in English and its cognate continuum in French no doubt contributes to the confusion.

However, this does not mean that francophone archivists have not acknowledged the limitations of the theory of the three ages of archives or recognised the need for archivists to intervene earlier in the life cycle of records. In Canada, Jean-Yves Rousseau and Carol Couture (1994) advocated for archivists to adopt an integrated intervention that would take into account at the same time the primary and the secondary values of the documents. Marcel Caya argued that the theory of the three ages was the product of the specific context of French administration in the 1960s and that it was becoming increasingly difficult to justify using it while the contexts of the creation, use and preservation of records had changed dramatically since then (Caya 2001-2002, 2004). Like the proponents of the Records Continuum Model, he believed digital records called for a rethinking of the ways records are managed in organisations and for the intervention of archivists in the design of recordkeeping systems (Caya 2004).

\section{Interviews with Swiss archivists}

The research conducted for this article is part of a larger study that is investigating the preservation of digital records in francophone countries. For the first stage of this research, in 2019, preliminary interviews were conducted in France and a small case study was organised in a Swiss canton. The second phase of the research, which would have included a larger study in France, and future plans to extend the research to other French-speaking countries have been delayed due to the COVID-19 pandemic. In this article, I report on the findings of the case study conducted in Switzerland. The study aimed to determine how the archivists were ensuring that important records were created, managed, preserved and made accessible over time. In that context, questions were asked to the interviewees about their understanding of the Records Continuum Model and its differences with the theory of the three ages. 
The small size of the Swiss canton made it relatively easy to recruit a representative sample of archivists both at the municipality level and at the state government level. I conducted semi-structured interviews with eight archivists working at different levels of administration in the canton in December 2019. Three of the interviewees worked in cantonal government departments, four at the municipality level, and one in the State Archives. They were selected as a representative sample of archivists working in the different levels of administration. The size of the sample may appear small. However, the interviewees constitute around $40 \%$ of the total number of qualified archivists in those roles in that canton. All interviews were conducted in French and recorded with the participants' permission. Given that most of these departments and municipalities only have one archivist, this article does not identify the canton and the government departments or municipalities for which the interviewees worked so as to preserve their anonymity and to conform to the ethics clearance for this research project. For the purpose of the analysis, the interviewees were randomly assigned numbers from 1 to 8: AS 1-8 (Archivist-Switzerland 1-8). The data were analysed in French and then translated into English for this paper. All the translations of quotations are my own.

In the Swiss canton where the interviewees work, each government department has one archivist. Their role may be more appropriately described as that of records managers who manage current records, but since some of them also manage department archives and since they all act as intermediaries between their department and the state archives and they all call themselves archivistes, they will be referred to as archivists in this paper. Some of the largest local councils also have qualified archivists attached to them and, in that case, it is appropriate to call them archivists because the local councils keep their own archives. The local councils that do not employ an archivist have archives officers (without an archives qualifications) to look after their archives. All the archivists interviewed for this paper have a qualification in archives management. Five were female and three were male, and they had occupied their current positions for between 5 and 24 years, with an average of 12.5 years.

The Swiss Federal Law on Archiving defines documents as "all information registered on any type of support, received or created within the context of carrying out the public activities of the Confederation, as well as all the research instruments and all the additional data that are necessary to understand and use that information", and archives as "the documents that the Federal Archives have taken over and preserve or that other departments archive themselves according to the principles stated in this law" (Swiss Confederation 1998, Art. 3). In line with the federal system, the Swiss Federal Law on Archiving only applies to the records of the federal government and each canton has its own archival law (Burgy and RothLochner 2002-2003). In practice, the cantons use a wide range of records management and archival systems, and a wide range of terminologies. An examination of the archival legislations in the seven cantons where French is an official language showed that each cantonal legislation used different definitions for the terms documents and archives and that none of them used the definitions adopted by the Federal Archives or definitions from international standards. In addition, although the French version of the life cycle model is not mentioned in the legislation of any of 
the French-speaking cantons, it is widely used in practice in the canton where interviews were conducted.

\section{Swiss archivists' understanding of the Records Continuum}

One of the cantonal government department archivists I interviewed, AS1, argued that the linearity of the French life cycle model corresponds well to the practice in Switzerland:

We still have a very linear view. We are not at all following the Records Continuum. We are managing the life cycle of the three ages. It is very linear, but at the same time, I realise that it corresponds well to the work processes of the public administration.

However, she felt that the "three ages" worked well for simple things, but not as well for long and complex projects, where people would like to keep records for longer, for example in the judicial field. Asked about her understanding of the Records Continuum, she replied that she had read the theory, but found it difficult to understand how it can be realised in practice. In particular, she mentioned reading an article on the Records Continuum that I have written in French for a Swiss journal (Frings-Hessami 2018), and trying to transpose an example given in that article to an activity with which she was familiar, but found it complicated. She commented that the Records Continuum "change all our temporal view of archives, which I think corresponds very well with European culture, with European history, ... [which] is very linear in that respect". She added that in Switzerland, "we don't anticipate", "we wait for the prescribed time to pass", "we say: "Well, we have 10 years, we have the time to wait and see". But she realised that "now, one must not think like that, one must stop to see things like that". She believed that if one adopts "a view centred on the citizens or on the people", "one will succeed better to approach and visualise Records Continuum theory, thinking, well, at some point, someone is considered to be an active citizen, then ... he will become history, and what will I take?... and to have a more tridimensional way and to make connections, rather than to have a linear way". However, she commented that it is difficult to find people who think that way: "When we discuss about that among archivists, we all agree about it, but to change everything, that is a titanic job!".

When asked if she understood the Records Continuum Model, another interviewee, AS7, replied "Yes, more or less. For me, it is always a bit the same thing, but presented a bit differently, the basis is the same. The same archive can have several functions, that's it, isn't it? And not necessarily three ages, three states, but several functions, that's right, that is another type of dimension". Her explanation was confused, on the one hand describing the model as similar to the life cycle model, and on the other hand, with the mention of several functions, picking on a key aspect of the model: the possibility for records to perform different functions for different stakeholders, and the existence of another "dimension"; not saying that these could be happening concurrently, rather than consecutively, but distinguishing the 
application of the Records Continuum from a linear application of the three ages of archives.

Similarly, AS5 said that she had heard a bit about the Records Continuum during her studies, but that she was not sure if she understood it well. Reflecting on an article she read recently about the model (Frings-Hessami 2018), her comments showed that she understood that the same record may be used differently by different people and may have different meanings. She commented: "Personally, I am in the context of a public administration. That is my point of view. I am not saying that afterwards, it won't be someone else's". She understood that there could be other uses by other users. However, she saw these uses as belonging in the future, and she was not concerned by them.

The representation of the model as four concentric circles can lead to confusion and give the impression that the circles are representing cyclic processes. One of the interviewees said that:

Presenting the Records Continuum in circles to show that it is a cycle with different phases like that ... in circles, to show that it is a process that does not end... [With the three ages of archives], we have the impression that there is a beginning, an end, and that after, it is finished, whereas the circles make it possible to see that after one gets to the stage of historical archives, one can still consult them, one can worry about format migrations, after all it is not finished, it is never finished. The circles of the Records Continuum appeal to me because of that. They show well that it is never finished, that there are several layers in the onion at all the levels, and that especially with the digital, formats preservation and all, it is a layer that is everywhere. That is really interesting.

The language used in these comments includes several terms that do not have a place in Records Continuum theory (cycle, phases, stages) and shows that this archivist did not understand that the circles in the model are meant to represent spacetime dimensions where processes are taking place, not cycles. If one was to talk of cycles in the Records Continuum Model, these would refer to the cyclic processes that are happening across the model (and therefore across the circles) with records moving from Create to Capture to Organise to Pluralise and back to Create and so on. However, if we look past those details and the uneasy language, the archivist showed that she understood essential aspects of the Records Continuum, including the simultaneity of processes,; and her conclusion was that she believed that the Records Continuum approach is "more complete".

AS6 also said that he had heard of the model during his studies. He understood that it requires archivists to intervene earlier in the lifespan of records, but his description of processes was linear. AS4 claimed that he understood the model and that he had been reading Archives and Manuscripts, the journal of the Australian Society of Archivists where the earliest articles on the Records Continuum were published, for more than 20 years. However, his ambition was to implement American-style records management in the department where he worked, rather than trying to adopt a Records Continuum perspective, and it was not clear how well he understood the model. AS2 also said that she had heard of the model, but she assimilated it to a technical system of records transfer, rather than to a conceptual model. 
The interviewees all showed that they understood the need for continuity between records and archives, and for measures to be taken early to ensure that records will be well managed and preserved, but they did not clearly understand the simultaneity of the dimensions of the Records Continuum Model. In the next section, I discuss some examples of actions that they take to encourage recordkeeping practices that will help ensuring that records that may need to be kept as archives will remain available over time.

\section{Recordkeeping processes and continuum actions}

One of the archivists interviewed, AS3, encourages people in her department to put a stamp or a mark on the records they believe should be preserved because of their historical value. She started with paper records, but she hoped that "if they start to reason like that, that will become a habit, they won't forget it when they will work electronically. At least, I hope so!" When talking to staff about electronic records, she also encourages them to think of the future needs to migrate the records to other systems. In particular, in relation to court records, she tries to raise the awareness of the magistrates so that they tell her which judgements are particularly important, which ones create a precedent.

Several of the archivists interviewed attempt-with various degrees of successto get accepted in IT projects from the beginning, which enables them to have a say in the choice of systems and therefore to ensure that records will be created and managed in formats that will permit their long-term preservation if required.

Moreover, AS3 tries to think of possible future uses of records from the time of their creation. She researches and documents their contexts in different ways. For example, she asks the press service for lists of judicial trials that made newspapers headlines, and she asks magistrates to mark the judgements that create a legal precedent. In those cases, she plans to keep the whole files, assuming that journalists or researchers will one day request access to them. In addition, she cuts out articles she finds in the local newspaper about important trials to "document the current times". She commented that:

When one has understood the theory, if one doesn't have tools, I was going to say state-of-the-art tools, it's no, it's no big deal, we make do with what we have. One can apply the Records Continuum with scissors [faire du Records Continuum avec des ciseaux] ... it seems to me.

She is not expecting those press clippings to be kept permanently with the records (although the newspapers and journals they are cut from may remain available in the cantonal library), but expecting that they will make the appraisal process easier 10 or 20 years later when she (or her successor) will need to appraise which files to keep. She also searches herself in law journals for articles relating to her canton, which would be another indication of the importance of the rulings discussed. Beyond the historical value of the records, she understands that records "help people to understand their past, their story, to reconstruct themselves" and she wants to encourage the preservation of records that she believes would help with this process. 


\section{Reflection on continuum, continuity and "continuum actions"}

The word continuum may be interpreted to imply a continuity, a sequence of actions that follow one another over time, following the Oxford Dictionary definition of the word: "a continuous sequence in which adjacent elements are not perceptibly different from each other, but the extremes are quite distinct" (https://www.lexico. com/definition/continuum). The word continuum has a similar meaning in French (https://www.larousse.fr/dictionnaires/francais/continuum/18628). When applied to the management of records and archives, it could suggest that there is a continuity between records and archives, that records and archives are managed smoothly in an integrated way over time, without there being strict distinctions between different stages in their life cycle that correspond to different ways of managing them. This would be in line with the way Canadian archivist Jay Atherton talked of a continuum of records and archives in his 1985 article "From Life Cycle to Continuum", where he distinguished the idea of a continuum from that of a life cycle, but did not reject completely the notion of stages, writing that: "All four stages are interrelated, a continuum in which both records managers and archivists are involved, to varying degrees, in the ongoing management of recorded information", working in a "symbiotic relationship" to achieve common aims, in an "ongoing cooperative interaction" to ensure common objectives, including "the creation of the right records, containing the right information, in the right format" (p. 48, 51). Although different from a strict application of a life cycle model, this interpretation of a continuum was still a linear approach.

By contrast in the Australian version of the Records Continuum, the term continuum is used to indicate multidimensional recursive processes through time and space. The Records Continuum Model is a spacetime model in which the four dimensions are happening at the same time and processes taking place in one dimension impact on what is happening in the other dimensions. As Brien Brothman pointed out 20 years ago, the Records Continuum perspective is actually closer to a cycle than to a line whereas the life cycle model in opposition to which it was developed is actually closer to a line than to a cycle:

The RC [Records Continuum] perspective carries intimations of a life cycle that leaves room for the unending circular, recursive, process that the notion of cycles imply [sic]. It discards the linear, unidirectional concept that the life cycle grew to become (Brothman 2001).

The Records Continuum does not reject cyclical views of reality (Upward 2000, p. 119), what it rejects is the idea of a record as an end product. Frank Upward has objected to the assertion that records would reach an "end product in the custody of archives" (Upward 2004, p. 42). The Records Continuum moved away "from notions of the archives as an end product to an emphasis upon the never-ending process of archiving" (McKemmish, Upward and Reed 2010, p. 4456). "Records are always in a state of becoming and never in a final state of being" (Upward 2004 , p. 40). The Records Continuum provides "a way of thinking about the integration of recordkeeping and archiving processes", within "integrated time-space 
dimensions"(McKemmish 1999, p. 195). "Records are 'fixed' in time and space from the moment of their creation, but recordkeeping regimes carry them forward and enable their use for multiple purposes by delivering them to people living in different times and spaces" (McKemmish 1999, p. 195).

The first ideas of a continuum of records and archives developed in Australia in the 1950s and 1960s by Ian Maclean and Peter Scott involved a continuity of actions, a "continuous view of the life of records", rather than a spacetime continuum, and they still encompassed the notion of an end product (Upward 2004, pp. 56-57). Maclean and Scott applied their thinking only to government records and they did not include considerations of social and cultural goals. According to Upward, "that approach was not a paradigm shift. It was part of the ongoing twentieth century search for continuity between archives and records management represented also in the use of the life cycle metaphor in European and Anglo-American archival theory" (Upward 2000, p. 118). On the other hand, he saw his ideas of Records Continuum based on a spacetime construct as a paradigm shift.

The Records Continuum and the life cycle models take on different spacio-temporal perspectives on records. Whereas life cycle models prescribe different treatments for records at different stages in their lives, the Records Continuum adopts a spacetime perspective that does not separate time and place and suggests that records may undergo different processes at the same time to enable them to perform different functions for different stakeholders. However, in practice, many of the processes applied to records and archives may be the same. Upward admitted that:

The advocates of both life cycle approaches and the [records] continuum have been pursing continuity of processes... In all countries we could ignore metaphor and speak directly about system design, recordkeeping and archiving processes, collaborative action, the development of continuous approaches from the point of creation, and so on (Upward 2000, p. 126).

The key differences between the Records Continuum and various versions of life cycles models reside in the proponents of the Records Continuum's rejection of the idea of end product and their belief that records are constantly in a process of being made and remade and that different processes can be applied to them at the same time to meet different needs. The Records Continuum opens the door to the acceptance of the subjects of the records as co-creators of the records and consequently to the creation of additional records and to the incorporation of different perspectives and additional metadata in the recordkeeping systems to meet their various needs and to help carry the records forward and make them accessible through time and space.

The misunderstandings of the Records Continuum among francophone archivists revealed in the literature review and through the interviews that I conducted for this article can partly be attributed to the ambiguity of the term "continuum", whose meaning in Records Continuum theory is different from its common usage in French and in English. Further research should be conducted in other French-speaking countries to ascertain how widespread these misunderstandings are among archivists. These misunderstandings are important because they impact on cross-cultural communication and on the development of collaborative recordkeeping projects and 
international standards. However, if we focus on the essence of the Records Continuum Model, which aims to ensure that records that all stakeholders will need in the short, medium and long terms are created, managed, preserved and made accessible to meet their needs without waiting until the records reach the end of their active use, we can separate the understanding of the model itself from the implementation of recordkeeping processes which may be aligned with the model. Small "continuum actions" taken by some of the Swiss archivists I interviewed, such as "applying the records continuum with scissors" or putting stamps on judgements that create a precedent, help to create, preserve and contextualise records that will be needed in the future to meet the needs of different stakeholders.

I suggest that some small "continuum actions" bring into recordkeeping practice a Records Continuum perspective that can help to meet the needs of multiple stakeholders within a life cycle framework. They facilitate the future work of archivists by providing them with ready to use information about the context of the records and aim to cater for the needs of various people who may want to access the records for various reasons. They help to embed the records in their societal context and to bring them into the fourth dimension of the Records Continuum.

Pluralisation is not just about sharing in the future. In order to be shareable in the future, records need to be well managed and embedded in their societal context from the time of their creation. They need metadata that relate them to their context. The newspaper clippings and journal articles collected by AS3 document the societal expectations that may be placed on records of some events to be kept and made accessible in the present or in the future due to their importance for some people or for the society as a whole. AS3 keeps those press clippings separate from the records and does not expect that future archivists will decide to preserve them after they use them to assist with appraisal decisions. She sees them as helpful for the appraisal process, but, modestly, affirms that she is only making suggestions and that she does not try to impose her own judgement. However, I think that she is too modest and that the clippings and notes that document her research and thought process deserve to be preserved with the records when they will be transferred to the State Archives. Even though the articles that she cuts out or copy may remain accessible from their source, they could be very useful for future users of the records who may want to understand their societal context.

Records are embedded in the societal context in which they were created from the time of their creation and need to be further embedded in that context so that they can be used by multiple stakeholders (Frings-Hessami 2021). The format, structure and content of records and the system in which they are captured reflect the context in which they were created. For example, court proceedings reflect the way laws are implemented. To be kept as evidence, records need to be captured in a recordkeeping system that capture information about their context and their evidential characteristics. The additional documentation kept by AS3 helps to contextualise the cases and as a consequence will assist the appraisal decisions that will need to be made by future archivists. They document other perspectives and details that are not included in the records. Moreover, their collection itself contributes to the appraisal process at the time it is performed, illustrating the fact that in Records Continuum practice, appraisal is "a multi-faceted recursive process which begins with defining 
what should be created (first dimension), what should be captured and managed as records (second dimension), what should be managed as part of individual or organizational memory (third dimension) and what should be pluralized beyond organizational or individual memory (fourth dimension)" (McKemmish et al. 2010, p. 4455). Putting stamps on records that should be preserved because of their importance for the broader society is also a fourth-dimension process.

These small actions can make a big difference. They complement the efforts made by archivists to put in place business classification schemes and retention schedules. They go further than a collaboration between records managers and archivists where archivists help with setting up processes that will ensure that records that have been created will be managed properly so that they can later become archives. They show that the records managers/archivists are thinking of future uses of the records, of future stakeholders, right from the beginning. This can be contrasted with recordkeeping systems and models that seek to achieve a continuum or continuity between records and archives. These systems only capture and preserve the perspective of the organisation that created the records. A Records Continuum perspective, on the other hand, recognises the rights of the people whose information is included in the records as co-creators of the records and, as a consequence, create, capture, preserve and make accessible records that reflect their perspective and meet their needs. This approach can also be contrasted with the fifth dimension that Lemay and Klein suggested to add to cater for other uses of the records only at the end of their life cycle when the records have been transferred to an archives, which would be too late for the many records that would not have been created or that would not have survived until that time.

\section{Conclusion}

The Records Continuum Model and life cycle models adopt different views of the management of records and archives over time and space. However, I argue that they are not completely incompatible. Beyond the differences in the conceptual models, what matters is what is done in practice to ensure that records that are needed to support business practices and regulatory requirements and to meet the needs of various stakeholders are created, managed and preserved as evidence of the activities they relate to and made accessible to those who need them over time and space. From that point of view, I argue that small "continuum actions" taken by records managers/archivists working within a life cycle framework can bring a Records Continuum perspective into their recordkeeping practice and can make a significant difference in the amount of records that will be created and will remain available over time and in the contextual information that will be preserved with them. When Swiss archivist/ records manager AS3 does research and collects articles and newspaper clippings to document the context of important events and the records associated with them, her thought process takes her through an assessment of the needs of the broader society for these records, which is a process that is part of the fourth dimension of the Records Continuum Model. By documenting the context of the records, she embeds them in their societal context to show their importance for the people involved in 
the events that they document and for the society of the canton as a whole and she increases the chances that these records will be preserved and remain accessible and useable. Although taken within a life cycle framework, these actions align with a Records Continuum perspective. This shows that notwithstanding the context in which they work, records managers and archivists can adopt measures that will help meet the needs of various users of the records in the short and in the long terms.

Acknowledgments The research for this paper was supported by a grant from the Whyte Fund, Faculty of Information Technology, Monash University.

\section{References}

Atherton J (1985) From life cycle to continuum: some thoughts on the records management-archives relationship. Archivaria 21:43-51

Bagnoud G, Fluckiger P, Leibenguth C, Marin P-H, Renevey Fry C, Tissot C, Zambrella A (2005) Archives publiques genevoises: un exemple de collaboration dans le domaine du records continuum [Public archives in Geneva: an example of collaboration in the domain of the records continuum]. Gaz Arch 197:97-113

Brothman B (2001) The past that archives keep: memory, history, and the preservation of archival records. Archivaria 51:48-80

Burgy F, Roth-Lochner B (2002-2003) Les archives en Suisse ou la fureur du particularisme [Archives in Switzerland or the rage of particularism]. Arch 34(1-2): 37-80

Caya M (2001-2002) Les vrais regards de Janus: les rôles complémentaires de la gestion des documents et des archives [The true eyes of Janus: the complementary roles of records and archives management]. Arch 33(2):3-20

Caya M (2004) La théorie des trois âges en archivistique. En avons-nous toujours besoin? [The theory of the three ages in archival science. Do we still need it?], paper presented at the École des Chartes, 2 December 2004. http://elec.enc.sorbonne.fr/conferences/caya. Accessed 4 Jul 2021

Chabin M-A (2012) Le records management: concepts et usages. https://www.arcateg.fr/wp-content/ uploads/2017/03/MAC-Le-Records-management.-Concept-et-usages-2012.pdf. Accessed 4 Jul 2021

Direction des Archives de France (1993) La Pratique archivistique française [French archival practice], coordinated by Jean Favier. Archives Nationales, Paris

Duchein M (1985) Les archives dans la Tour de Babel: problèmes de terminologie archivistique internationale [Archives in the Tower of Babel: problems of international archival terminology]. Gaz Arch 129:103-113

Frings-Hessami V (2018) La perspective du continuum des archives illustrée par l'exemple d'un document personnel [The perspective of the Records Continuum illustrated by the example of a personnel record]. Rev Electr Suisse Sci Inf 19. http://www.ressi.ch/num19/article_149. Accessed 3 Oct 2021

Frings-Hessami V (2019) Le records continuum et la tradition archivistique australienne [The records continuum and Australian archival tradition]. Archivistes! 129:8

Frings-Hessami V (2021) The societal embeddedness of records: teaching the meaning of the fourth dimension of the Records Continuum Model in different cultural contexts. Arch Sc 21(2):139-154

Frings-Hessami V, McKemmish S (2021) Records continuum. In: Franks P (ed) The handbook of archival practice. Rowman \& Littlefield, pp 54-57

French Republic (1979) Loi n ${ }^{\circ} 79-18$ du 3 janvier 1979 sur les archives [Law number 79-18 of 3 January 1979 on archives]. https://www.legifrance.gouv.fr/loda/id/JORFTEXT000000322519/. Accessed 4 Jul 2021

Gilliland AJ (2017) Archival and recordkeeping traditions in the multiverse and their importance for researching situations and situating research. In: Gilliland AJ, McKemmish S, Lau AJ (eds) Research in the archival multiverse. Monash University Publishing, Clayton, pp 31-73

Kern G, Holgado S, Cottin M (2015) Cinquante nuances de cycle de vie [Fifty nuances of life cycles]. Cah Numér 11(2):37-76 
Ketelaar E (1997) The difference best postponed? Cultures and comparative archival science. Archivaria 44:142-148

Ketelaar E (2001) Ethnologie archivistique [Archival ethnology]. Gaz Arch 192:7-20

Klein A (2014) Pour une vision dialectique [Towards a dialectical vision], paper presented at the 2nd Annual Conference of the ICA, Archives and Cultural Industries, Girona, Spain, 11-15 Oct 2014. https://www.girona.cat/web/ica2014/ponents/textos/id5.pdf. Accessed 4 Jul 2021

Klein A (2019) Archive(s), mémoire, art: éléments pour une archivistique critique [Archive(s), memory, art: elements for a critical archival science]. Presses de l'Université Laval, Quebec

Lemay Y, Klein A (2014) Les archives définitives: un début de parcours: revisiter le cycle de vie et le records continuum [Permanent archives: the start of a new path: revisiting the life cycle and the records continuum]. Archivaria 77:73-102

McKemmish S (1994) Are records ever actual? In: McKemmish S, Piggott M (eds) The records continuum: Ian Maclean and Australian archives first fifty years. Ancora Press, Clayton, pp 187-203

McKemmish S (1999) Yesterday, today and tomorrow: a continuum of responsibility. In Horsman PJ, Ketelaar FCJ, Thomassen THPM (eds) Naar een nieuw paradigma in de archivistiek. Jaarbook 1999 [Toward a new paradigm in archivistics. 1999 Yearbook]. Stichting Archiefpublicatie, 's-Gravenhage, pp 195-210. https://kvan.courant.nu/periodicals/JB/1999. Accessed 4 Jul 2021

McKemmish S (2001) Placing records continuum theory and practice. Arch Sci 1(4):333-359

McKemmish S, Upward FH, Reed B (2010) Records continuum model. In: Bates MJ, Niles-Maac M (eds) Encyclopedia of Library and Information Sciences, 3rd edn. Taylor \& Francis, New York, pp 4447-4459

Millar LA (2017) Archives principles and practices, 2nd edn. Facet Publishing, London

Pérotin Y (1961) L'administration et les "trois âges" des archives [Administration and the "three ages" of archives]. Seine et Paris 20:31-33. https://web.archive.org/web/20140212100751/piaf-archives.org/ sites/default/files/Administration_et_les_trois_ages.pdf. Accessed 4 Jul 2021

Pérotin P (1966) Administration and the "three ages" of archives. Am Arch 29(3):363-369

Piggott M (2012) Archives and societal provenance: Australian essays. Chandos Publishing, Oxford

Rajotte D (2010-2011) La réflexion archivistique à l'ère du document numérique: un bilan historique [Archival reflection in the era of digital documents: a historical assessment]. Arch 42(2):69-105

Rousseau J-Y, Couture C (1994) La place de l'archivistique dans la gestion de l'information. In Rousseau J-Y, Couture C (eds) Les fondements de la discipline archivistique [Foundations of the archival discipline]. Presses de l'Université du Québec, Quebec

Soum-Paris P (2021) "La Tour de Babel", 35 years later: challenges and tools relating to the translation of archival terminology from English to French. Arch Manuscr 49(1-2):8-36

Swiss Confederation (1998) Loi fédérale sur l'archivage [Federal Law on Archiving]. https://www.admin. ch/opc/fr/classified-compilation/19994756/201305010000/152.1.pdf. Accessed 4 Jul 2021

Upward F (1996) Structuring the records continuum part one: post custodial principles and properties. Arch Manuscr 24(2):268-285

Upward F (1997) Structuring the records continuum part two: structuration theory and recordkeeping. Arch Manuscr 25(1):10-35

Upward F (2000) Modelling the continuum as paradigm shift in recordkeeping and archiving processes, and beyond-a personal reflection. Rec Manag J 10(3):115-139

Upward F (2004) The records continuum and the concepts of an end product. Arch Manuscr 32(1):40-62 Williams C (2006) Managing archives: foundations, principles and practice. Chandos, Oxford

Publisher's Note Springer Nature remains neutral with regard to jurisdictional claims in published maps and institutional affiliations. 